\title{
BIOGRAFÍAS Y REDES EN EL COMERCIO DEL CAFÉ ENTRE ALEMANIA Y AMÉRICA CENTRAL. 1920-1959. CHRISTIANE BERTH. CHIAPAS: CIMSUR-UNAM, 2018
}

Gertrud Peters Solórzano

Recibido: 14/07/19 - Aceptado: 22/07/19

Hace más de una década conocí a Christiane en ocasión de un congreso centroamericano de historia en San José. Iniciaba ella su labor de investigación sobre la inmigración alemana en Costa Rica durante el siglo XX por medio de fuentes biográficas, entrevistas y documentos del Archivo Nacional de Costa Rica. En ese entonces, éramos varios académicos interesados en la historia de los negocios de alemanes-costarricenses durante el siglo XX. Margarita Torres y mi persona habíamos terminado una investigación con los archivos de la Junta de Custodia de los bienes de países totalitarios en Costa Rica, trabajando con la Escuela de Historia de la Universidad Nacional en el año 2002. ${ }^{1}$ Asimismo, Carlos Meissner estaba investigando arduamente, en su tesis doctoral, a este grupo de alemanes-costarricenses y recolectando información de cada una de esas familias desde su arribo al país y hasta después de la segunda guerra mundial. El enunciado de Meissner podría resumirse en que, a pesar de la catástrofe que sufrieron los alemanes costarricenses con sus propiedades y la deportación en la segunda guerra mundial, este grupo tuvo la resiliencia de volver a fundar sus negocios en Costa Rica años después. ${ }^{2}$ También, Dennis Arias de la Universidad de Costa Rica, estaba investigando la presencia alemana en Costa Rica durante la época del nacionalsocialismo. ${ }^{3}$ Todos estos trabajos junto al de Christiane ${ }^{4}$ se complementaron por sus diversos enfoques históricos y por el intercambio de ideas, de documentos históricos y bibliografía concerniente a cada particularidad en estudio.

Me da mucho gusto, reseñar su reciente y valioso libro donde analiza el nexo entre el puerto de Hamburgo con tres universos cafetaleros: Costa Rica, Guatemala y Méjico desde 1920 hasta 1959. Esta obra aporta a la historiografía alemana y centroamericana una comparación de esos tres escenarios geográficos e históricos por medio de fuentes novedosas consultadas e interpretadas rigurosamente. Entre ellas, las biografías, las entrevistas en los tres espacios geográficos y la recolección de información en los archivos de Costa Rica, Guatemala, Méjico, los Estados Unidos y Alemania. Además, de archivos privados, testimonios, correspondencia y autobiografías. 
El primer capítulo es la Introducción del libro donde Berth considera tres aspectos históricos y teóricos para enmarcar su estudio: En primer grado las redes comerciales entre el viejo mundo y América Central. ${ }^{5}$ En segundo lugar, el rol jugado por los alemanes inmigrantes y su percepción del mundo del café en Centroamérica. Y, por último, el significado que tenía este grano centroamericano para los importadores en Hamburgo.

Berth utiliza y debate conceptos de reflexión como la historia global alrededor del café y la transaccionalidad de las redes comerciales, sociales y culturales. Muy cuidadosa de apuntar las diferencias espaciales sobre la inmigración alemana y su incursión en la producción cafetalera en Costa Rica, la Alta Verapaz en Guatemala y Soconusco en Méjico. Afirma ella que, el negocio del café por empresarios alemanes fue conformado por redes y por su inclusión en otros negocios en los países mencionados. Por otro lado, el café había sido un negocio que traspasa fronteras y donde la confianza era primordial para proveer un producto de calidad y en la cantidad pactada. Con el fin de asegurar su negocio, estas redes alemanas se integraron a las élites nacionales y locales, además, de recibir el respaldo de sus diplomáticos, ya fuera en tiempos de crisis o de bonanza.

El orden de sus ideas en su libro es coherente con su objetivo general y también temporal, va más allá de 1920 a 1959 y su investigación abarca hasta mediados desde el siglo XIX, cuando se inició la inmigración alemana a Centroamérica y las exportaciones de café hacia el mercado alemán. Partiendo de una introducción amplia, Berth divide su capítulo en cuatro segmentos: el comercio del café entre Hamburgo y Centroamérica, la metodología utilizada en este trabajo, el estado de la investigación y la importancia de trasponer distintas fuentes y de distintos países en ambos continentes.

El segundo capítulo se titula "Historias de la globalización: el comercio del café y la inmigración alemana en América Central en el siglo XIX". La construcción de las redes comerciales y la inclusión de los alemanes en el café fue distinta en Costa Rica, la Alta Verapaz y Soconusco. Costa Rica se integró más temprano a la economía del café de forma intensiva y la comunidad de alemanes se asentaron alrededor de la ciudad capital y en menor cuantía, en los puertos. La Alta Verapaz y Soconusco incursionaron en el café tardíamente, y las fincas con sus beneficios se situaron en regiones alejadas o marginales desde las capitales de esos países. Esta primera generación de inmigrantes germanos percibió una oportunidad en el negocio del grano por la creciente demanda de Europa y la utilizó para cerrar contratos entre los actores en el viejo mundo y el nuevo. La autora hace referencia de la crisis de sobreproducción de café de fin de siglo XIX y de cómo afectó las relaciones comerciales entre el mercado local e internacional y, en las relaciones entre los actores de los dos continentes. El quehacer en el café no estuvo exento de dificultades, como explicará la autora en los próximos capítulos. 
"La fragilidad de las redes en la década de 1920: las crisis de la posguerra, la nueva inmigración y los “años dorados" de 1924 a 1928" es el tercer capítulo de esta obra. Inicia con la primera guerra mundial, la crisis en el mercado europeo y en estas redes trasnacionales. Además, en Centroamérica se dieron golpes de estado que influyeron en las relaciones entre Alemania, los actores sociales y políticos y los inmigrantes alemanes. Por otro lado, decenas de alemanes post guerra decidieron emigrar hacia Centroamérica y poseían características distintas a la emigración del siglo XIX, muchos de ellos eran empleados o personas sin recursos que incomodaron a sus mismos nacionales, ya asentados en Centroamérica. A partir de mediados de la década de 1920 se produjo una bonanza en los precios del café, que atrajo un repunte en el mercado alemán y Centroamericano. Sin embargo, no todos tuvieron éxito y Berth nos relata la historia de un fracaso, "Der Tropenzauber", o sea la magia del trópico que atraía a muchos de estos inversionistas alemanes, pero que podían sucumbir en tiempos de crisis.

El cuarto capítulo "El comercio del café en tiempos de crisis: la crisis económica mundial, los gobiernos autoritarios y el nacionalsocialismo". Época de baja de precios, de descenso en la importación de café centroamericano y de nuevas formas de manejo y control del mercado por el nuevo gobierno alemán. Algunos empresarios no pudieron mantenerse en pie cuando los precios cayeron a niveles de no poder salir ni con los costos de la producción ni del comercio del café. Afirma Berth que dos gobiernos autoritarios en Centroamérica, Ubico en Guatemala y León Cortés en Costa Rica, ascendieron al poder igual que en Alemania surgió el nacionalsocialismo. Si ben las exportaciones de café aumentaron hacia Alemania y algunas empresas en Costa Rica marcaron un aumento inimaginable, tal vez, se podría distinguir entre el autoritarismo de Ubico y de León Cortés. La crisis de 1932 a 1936 la llevó a sus espaldas el presidente Ricardo Jiménez y más bien, el estado costarricense junto a distintos actores cafetaleros negoció un acuerdo de crear el Instituto de Defensa del Café de Costa Rica para regular el beneficiado, la exportación y el torrefactado del café. La imagen negativa de León Cortes (1936-1940), que era germanófilo, pudo ser provocada y difundida ampliamente por sus contrincantes políticos para eliminarlo de la posibilidad de volver a ser presidente de la República en la campaña electoral 1943-44. Es un hecho que las exportaciones de café aumentaron hacia Alemania y por medio de su moneda, el marco aski, subieron las importaciones de mercaderías alemanas hacia Centroamérica, ayudado también con la política del gobierno nacionalsocialista y la ganancia que obtuvieron algunos exportadores de café alemanes, no solo con el café producido en sus fincas, sino también con la cosecha de otros productores y beneficiadores costarricenses. Por otro lado, Berth explica cómo hubo empresas judías en Alemania que sufrieron injustamente de la "arianización" con el fin de despojarlas de sus actividades en el mercado. Para obtener más claro el papel de los alemanes cafetaleros que se vieron favorecidos en esos años, la autora nos relata el ascenso de 
Friedrich Köper quien por sus raíces étnicas logró llegar a los primeros lugares en la exportación de café guatemalteco de la época.

El quinto título es "Fragmentación de las redes del comercio cafetalero: la segunda guerra mundial, internamientos y expropiaciones". Este capítulo es una historia oculta en la educación centroamericana, por lo menos para Costa Rica. Christiane Berth explica la manera cómo los Estados Unidos sobre estimó la influencia del NSAP-AO en América Central para romper las redes conformadas por los alemanes y su enlace con las elites locales y nacionales. La primera acción fueron las Listas Negras o Proclamadas confeccionadas por Londres y Washington y aumentadas por los gobiernos centroamericanos de turno en julio de 1941. Después continuaron nuevos controles, en especial sobre los cafetaleros alemanes pues se les prohibió exportar su producto a los Estados Unidos, único mercado abierto que, además le interesaba tener el monopolio de este grano para abastecer no solo a su población, sino a su ejército. Los alemanes fueron detenidos, internados y enviados hacia campos de internamiento a los Estados Unidos con la bendición de los gobiernos de Costa Rica y Guatemala. Como paso seguido, esos gobiernos expropiaron, confiscaron y obligaron a los enlistados a vender sus propiedades y negocios. En la mayoría de los casos, alemanes y sus familias fueron expatriadas a su país de origen y como resultado de todas estas medidas, el gobierno norteamericano, guatemalteco y costarricense fragmentaron sus redes comerciales, sociales y políticas.

En la sección seis: “La década de 1950: el regreso de los descendientes alemanes y la reconstrucción de las redes comerciales", la autora manifiesta que el retorno de los alemanes deportados hacia los Estados Unidos y algunos hacia Alemania, fue una empresa difícil. Me surge una pregunta: si la naturalización de estos alemanes fue impuesta por los gobiernos centroamericanos para conseguir el permiso del gobierno y volver a Costa Rica y Guatemala. La reconstrucción de las redes comerciales entre Alemania y Centroamérica fue un proceso lento y lleno de dificultades dadas las inclemencias de la posguerra en Alemania y el atraso en acuerdos de paz de Guatemala y Costa Rica con la República Federal Alemana; en especial, si los gobiernos continuaban expropiando propiedades de los enlistados o no estaban anuentes a pagar las indemnizaciones. La importación de café estuvo limitada durante varios años hasta que en octubre de 1955 fue liberalizado este producto por el gobierno alemán y de allí en adelante fue creciendo con los años.

El epílogo que nos propone la autora resume la ruta que llevó a cabo el café centroamericano en Alemania y los Estados Unidos, los cambios que sostuvieron los cafetaleros descendientes de alemanes ante el Acuerdo Internacional del Café en 1962 y la "Americanización del café" cuando este grano centroamericano perdió su 
importancia en el mercado de Hamburgo, pero en los Estados Unidos se inició una moda por consumir cafés gourmet provenientes de Centroamérica.

Al final, Christiane Berth divide su conclusión en dos apartados: Primero, cómo se adecuaron las redes en tiempo de crisis de precios y de políticas comerciales que, atentaron contra los negocios de estas redes trasnacionales en un mundo global desde mediados del siglo XIX hasta finales del XX. En especial, en la segunda guerra mundial cuando el café fue pieza fundamental en la expropiación, deportación y puesta en campos de internamiento de los alemanes de Centroamérica de los Estados Unidos. En segundo lugar, las percepciones de los mundos del café y las biografías en su comercio, la manera cómo funcionaron las redes de aquellos inmigrantes que iniciaron sus fincas y negocios en la Centroamérica del siglo antepasado y que en los tiempos de crisis fueron más frágiles sus redes familiares y comerciales. Las nuevas generaciones optaron por diversificar sus negocios y hoy día "el significado del café centroamericano para el mercado alemán se ha ido reduciendo cada vez más desde la década de $1980^{\prime \prime}{ }^{6}$

\section{Notas}

1 Peters, Gertrud y Margarita Torres. “Cambios en la propiedad agrícola en Costa Rica durante la Segunda Guerra Mundial”. Universidad Nacional, Escuela de Historia, 2002. Puede verse también el estudio de fuentes en Archivo Nacional de Costa Rica de las mismas autoras: "Los Archivos de la Junta de Custodia de Costa Rica durante la Segunda Guerra Mundial: ciudadanos y empresas en las diferentes listas construidas por el gobierno británico, estadounidense y costarricense". En Revista de Historia. No. 46, 2002. Recientemente, Gertrud Peters publicó la obra El negocio del café de Costa Rica, el capital alemán y la geopolítica, 19071936. Heredia EUNA, 2016.

Meissner, Carlos. A Resilient Elite: Germans Costa Ricans and the Second World War. Disertation Doctoral. University of York. 2010.

“La presencia alemana en Costa Rica durante la era del nacionalsocialismo (1933-1941)". Revista de Historia, Nos. 53-54, pp. 195-220. Su tesis La recepción critica del nacionalsocialismo entre la intelectualidad de izquierda en Costa Rica (1933-1943), tesis de maestría inédita, Universidad de Costa Rica. 2006.

Berth, Christiane. "La inmigracion alemana en Costa Rica: migración, crisis y cambios entre 1920 y 1950 en entrevistas con descendientes alemanes". Revista de Historia de América, 137, pp. 9-31.

Se podría mencionar mejor a Centroamérica que a América Central como espacio geográficohistórico porque en la historia colonial de este estrecho se incluía a la región de Chiapas y se excluía a Panamá.

Berth, Christiane. Biografías y redes en el comercio del café entre Alemania y América Central. 19201959. Chiapas, CIMSUR-UNAM, 2018. 
Gertrud Peters Solórzano. Costarricense. Historiadora por la Universidad de Costa Rica (UCR) y graduada en Administración de Empresas por la National University San Diego, California. Tiene experiencia en la historia económica de Costa Rica, en especial en la historia agroecológica y cafetalera, la historia empresarial, la inversión extranjera y los grupos de poder económico.

Contacto: petersgertrud.cr@gmail.com

ORCID: 0000-0001-7038-8301 